\title{
UNCOVERING THE MULTIDIMENSIONAL IDENTITY OF THE HUMAN SELF
}

\author{
ELŻBIETA MAGDALENA WĄSIK
}

\section{Introduction}

This article discusses the multidimensionality of communicative identity of human selves which finds manifestations in their interpersonal encounters and intersubjective understandings. Therefore, its subject matter is the distinction between personal and social identity types considered in terms of conscious states of human selves, resulting from their sense of uniqueness, sameness in time, awareness of separateness from other individuals, and, at the same time, sharing similarities with other members of different social, cultural, or ethnic groups to which they belong. Psychic faculties and/or mental competences of human selves as thinking subjects in perceiving and memorizing or remembering, contemplating and imagining, reasoning and concluding, appraising and valuing, which proceed along with their semiotic performances as communicating persons, are regarded as prerequisites for the growth of their multiple identities, depending altogether on language and culture.

\section{Multiple selves as a result of multidimensional identity perception}

The knowledge about the self, or the self-awareness, includes mental propositions, i.e., intelligible judgments, convictions or beliefs of the individual - realizing his or her distinctiveness and position in relation to others - who is able to formulate concrete, sensorially perceivable statements about him- or herself. One can, however, obtain a complete image of the self only then when one looks into complex reactions of its organism to itself and its environment at a certain moment. In order to 
understand the human individual, one has to study his or her involvement in the actual communicative situation. For this purpose, worth considering is the theoretical contribution of Joseph Samuel Bois (The Art of Awareness 18-23), who proposed a phenomenological approach to the nature of man, having been earlier developed by Alfred Korzybski, an American scholar of Polish origin, in his book Science and Sanity. What constituted a novelty in comparison to the traditional definition of man as a rational animal was Korzybski's interdisciplinary outlook on the psychobiological complexity of human beings. Pursuant to Korzybski's and Bois' depiction of man as the so-called semantic reactor, the human organism as a whole continuously responds to stimuli of all kind. Therefore, man, reconstituted later by Joseph A. DeVito (The Interpersonal Communication Book 63-79) as the human self within the framework of communication theory, has to be seen as a set of psychosomatic activities of four kinds, such as (1) electrochemical activities, (2) self-moving activities, (3) feeling activities, and (4) thinking activities, involving symbolization. Constituting a complex and integrated living system, it consists of the closely related intraorganismic and extraorganismic activities in question, understood as its semantic reactions to the inside and outside world, and, as such, should be investigated and described.

Assuming that the identity of man is the product of his self-consciousness, it is right, in agreement with Korzybski's viewpoint, to approach the self in terms of the semantic reactor, that is, the activities which together make a person. In fact, they jointly create the man's conception of himself in relation to the others, while determining his subjective emotional experiences, sense of individuality, self-image and self-esteem. As it results from Korzybski's and Bois' reasoning, self-perception and self-identity of the individual are environmentally conditioned. However, the self exerts also impacts on his or her environment having physical, social, psychic and cultural dimensions. The self, as the initiator and responder, operates in a place or situation of social life, in a friendly or hostile atmosphere, in the face of prevailing value systems, codes of behaviors, and in relation to time. Its functioning is significantly influenced by its past experiences and the future that it anticipates. Being a product of its past and imagined, planned future, the self is continuously in the state of becoming; it constantly develops from its experiences and expectations as

a unique being. Accordingly, at least seven aspects of the self, important for its sense of identity, can be concluded on the basis of its depiction as the semantic reactor, that is, its physical, emotional, social, cultural, present, past, and future aspects.

For the purposes of the theory of communication, Larry Barker (Communication 109-133, cf. especially 111) points out that the individual usually discovers many of his or her selves, sometimes contradictory, conflicting, and/or competing that result from its miscellaneous experiences gathered in different times and situations. The self as a subject is responsible for the unity of its mental states that result from its experiences gained from the first-person perspective, and may radically differ from 
one another. In agreeing with the depictions of the self as presented by Barker, it is right to distinguish such its dimensions, as (1) experiencing of singularity and individuality of its own body as an object localized in space and time, (2) experiencing of oneself in relation to others and through the eyes of others, i.e., under the influence of the picture of self that it assumes that others have of it, (3) experiencing of its own ever-changing drives and needs as well as feelings and emotions, (4) experiencing of its own thoughts and reflections in the form of internal, verbally conducted monologs that refer to events taking place in its individual life, (5) experiencing of the dynamics of its own action, performed, on the one hand, in accordance with repeating patterns, but, on the other, determined by the specificity and changeability of the (social) situations, (6) experiencing of its own public self - being the result of self-presentation and the opposite of the private self as not known to others - that is, of such an image of self that is single-handedly and deliberately projected by itself to others, (7) the sense of durability and stability of its own corporeal and spiritual existence over time, closely related to memory, especially its ability to recall its own emotional, volitional and cognitive experiences (and states), as (8) continuity of the own past and present selves, and (9) tensions (conflicted states of the ego) between the present (current) and future selves. In view of the multidimensionality of the individual and social selves, researchers of human communication focusing on human individuals face the challenge of coping with the issues of stability of their identities experienced in spite of the changeability of the states of their ego in changeable contexts and situations.

\section{Identification in the development of signifying and communicating behavior of man}

Identity as a topic of anthropological studies, dealing with the emergence of language as a species-specific property of mankind, was discussed in the light of the evolution of human abilities to communicate with use of verbal symbols. In the view of anthropologists (whose articles are included in the Handbook of Human Symbolic Evolution, edited by Andrew Lock and Charles R. Peters), the use of verbal signs, in the same way as nonverbal signs, is for interpersonal communicators something more than to signify objects from the environment. In truth, labelling objects, including oneself, amounts to the identification of them according to some of their categorical properties. While alluding to Leonard Rolfe ("Theoretical Stages in the Prehistory of Grammar" 779-784), the argument has to be provided for supporting the hypothesis of the emergence of (proto)language along with the development of social relationships. As Rolfe maintained, appropriate means of expression, preserved, inter alia, in grammatical patterns, must have been elaborated on different stages of evolution, that is, in the course of evolving the dialogic system of communication. 
In his argumentation pertaining to identification acts through giving names, Rolfe has stated that language facilitates thanks to its communicative functions (1) to formulate semantic and pragmatic contents and (2) to voice mental representations and communicative intentions. First of all, getting in touch with members of the own species necessitates a whole range of behaviors, which include the sequence of activities, such as addressing, attending, soliciting, complying, or refusing, acknowledging, and closing-out, narrating or expressing the opinions about public, objective, and generalized knowledge with the elimination of, at least to some degree, the subjective viewpoint of the speaker. The communicative behavior, which takes place between the forms of address and narration -involving ostension, as a simple form of deixis (demonstration or reference), identification and thematization - results, as Rolfe believes, from a variety of communicative needs. These kinds of behavior are motivated by intentions of communicators, leading first and foremost to the creation of interpersonal collectivities. Such groupings as clusters or networks of people arise when individuals as interpersonal communicators externalize verbally their intentional states through: (1) ostension, pointing to perceivable objects in non-verbal gestures and spatial, temporal, or directional deixis, (2) identification, naming objects of perception and thought, as well as (3) thematization, voicing subjective assessments, associations, and relations that exist between objects, experienced by themselves as the first and second persons engaged in a given action, and the third person(s) who remain(s) in various relations to a narrated communicative event. Admittedly, ostension is speaker-oriented, but the addressee, thanks to his or her intersubjective abilities, is able to understand what is pointed at as being seen from the place or position of the speaker. Therefore, it has to be acknowledged that the process of labelling, or exactly saying, identification and naming, builds on ostension. In the evolution of communication, ostension must have been undoubtedly reworked into labelling in order to produce a more symbolic form of reference, mainly when far-distant indication could no longer be supported by inferences drawn from the situation of the dialog. In the light of hypotheses regarding the formation of communicative abilities of humans, the sense of individual identity is an effect of creating social meanings and coming to attach labels to oneself as an object among the other objects in the world.

From the evolutionary point of view, the emergence and development of language has also contributed to significant changes in the life of humans and social order, described, inter alia, by Andrew Lock and Kim Symes ("Social Relations, Communication, and Cognition" 222-223), such as, firstly, the centralization of social power, secondly, the creation of social codes of conduct governed by social pressure, thirdly, the differentiation of society and specialization of roles, fourthly, the development of more explicit forms of communication in effect of decrease in the number of presuppositions shared by group members, and finally, the increase in the number of problems removed in space and time from immediate circumstance. 
The growth of language must have also strongly influence self-perception and selfunderstanding among members of primitive speech communities, who, in the face of the increase of social awareness and societal transformations, must have paid more and more attention to the effectiveness of communication, in order to improve their self-presentation, and to better articulate the self.

Reflecting on communicative functions of language from the times of its emergence, Lock and Symes ("Social Relations, Communication, and Cognition" 204-235, especially 222) accept the view, according to which the sense of identity and the ways of conceptualization of one's self are constructed and contained in behavioral and linguistic resources of collective practices within which individuals are socialized. In fact, what is being referred to through language has itself been created, similarly to the development of self-identity in effect of social encounters, through pragmatics of social communication. Apparently, there are no such cross-cultural studies which would facilitate the comparison of the conceptions of self and identity in the languages of the world, for example, with reference to the social structure or other environmental factors. Nonetheless, some samples of peculiarities, which are cited by Lock and Symes, testify that the understanding of the self who functions in interpersonal relations and the conceptualization of the identity in relation to the distinctiveness and uniqueness of individual selves across cultures are not the same. What is known from linguistic data is the fact that the speakers of Eskimo languages, using specific suffix-systems to express relationships between self and others, do not have a very strong sense of personal identity. On the contrary, Wintu Indians of Northern California think about the identity of the self in terms of grammatical categories provided by their language to express interpersonal relations and otherness, while defining it as a concentration of gradually fading features which give place to the features of the other. As the discussed authors prove, the Indians of the Wintu tribe sometimes perceive as the self what the speakers of European languages recognize as other.

By and large, Lock and Symes classify different conceptions of self in human cultures with reference to two orthogonal dimensions, such as (1) internal versus external, and (2) in control versus under control. Examples of the peoples having at disposal incompatible conceptualizations of the first person are the Dinka of the Sudan, who consider themselves, in terms of the self, as being under the control of external agencies, and the Māori, the Polynesian people of New Zealand, whose individual members perceive themselves as beings controlled by internal, inherent agencies. A comparison of the ways in which the first person is conceptualized in different languages of the world, in relation to the second and third persons defined by the roles of communication participants, would probably provide convincing evidence of how a given language can influence the development of self-consciousness of its individual speakers. 


\section{The linguistic concepts as mental signs of self-identification}

Despite the fact that some linguistic and cognitive abilities are common to all humans, there are social and cultural differences in the perception of reality and the expression of mental contents, including the perception of self in relation to others as well as the manifestation of one's own distinctiveness and consistency. Mental processes involved in language acquisition, language attrition, language production and language comprehension have been scrutinized and described enough that it is possible to conclude, among the other things, about the linguistic mechanisms of (self-)identification. In allusion to this question, experimentally inclined philosophers and psychologists, such as Franz Brentano (Psychologie vom empirischen Standpunkt) and Karl Bühler (Theory of Language), have provided evidence that the human mind is accessible only in an indirect way through the examination of the significative and communicative behavior of individuals and/or its products. On the opposite pole, there are cognitive psychologists of present times who claim that they are able to arrive at mental schemata of some clearly detached entities as psychic representations of extralinguistic reality. In their studies, cognitivists, following, inter alia, the investigative postulates put forward by Ulric Neisser (Cognitive Psychology), deal with concepts and images as mental signs of concrete and abstract objects that constitute for them cognitive units of human perception and memory.

The subject matter of Neisser's scholarly interests in the domain of cognitive psychology is the human self with respect to the origin of knowledge as an autospecifying information. For Neisser ("Five Kinds of Self-Knowledge" 36-54), the self being an object of perception and thought emerges due to certain mechanisms of assembling knowledge which enable human individuals to recognize themselves. A coherent and indivisible self is experienced in effect through an amalgamation of one's own knowledge coming from (1) perceptions of bodily relationships with the physical environment (i.e., the ecological self), (2) perceptions of immediate unreflective interactions with other persons (i.e., the interpersonal self), (3) memorizations and anticipations of actual and potential inter-actions and/or -relations (i.e., the extended self), (4) appreciations of the unavailability of conscious experiences to other people (i.e., the private self), and (5) assumptions, pertaining to human nature and differences between people, their social roles, individual attributes, etc., resulting from human abilities of conceptualization, derived from social life and culture.

Bearing in mind the fact that mental phenomena are traces of experienced contents fixed in the minds of human individuals, Neisser (inter alia, "Five Kinds of Self-Knowledge" 52-56; "Concepts and Self-Concepts" 3-4) deals with the conceptual self which is a mental representation of what comes to mind when one thinks about oneself. Even though it has at least five cognitively different aspects, ecological, interpersonal, extended, private and conceptual, it is coherent because it draws its meaning from the conceptual network preserved in language. Bearing in mind the 
nature of language, Neisser points out that: (1) self-concepts are never fully congruent with the self, especially as real things are distinct from the concepts that refer to them, though not independent, (2) particular cultures induce different kinds of self-concepts and, to some extent, support the development of different selves, (3) the self-concepts of humans most probably reflect, in the first instance, their properties as active embodied agents in natural and social environments, that is, their ecological and interpersonal selves, (4) the conceptual selves must be understood in contexts, (5) the self-concepts are practically sets of beliefs about oneself, but there are differences between what people say about themselves and what they in reality believe.

Practitioners of cognitive sciences analyze the nature of thought processes within the mind of individuals in connection with their experiential and mental abilities to perceive and memorize certain observable properties and aspects of reality. They depart from the assumption that perception and memory are, on the one hand, dependent on linguistic aptitudes and skills of human beings to communicate with one another through externally produced verbal means and, on the other, influenced by internal states of their minds experienced at every particular moment, motivated by their believes, desires, etc. A successive diversification of investigative objects and investigative perspectives in the study of mind, language and cognition causes that some representatives of language studies are forced to exceed the investigative domains of psychology. The argument that the human mind is constantly engaged in making mental representations of cognized objects from observable reality, with which human individuals interact and with which they indispensably establish relationships, has inspired, inter alia, cognitive linguists. Hereto belong studies, initiated by George Lakoff and Mark Johnson (Metaphors We Live By), George Lakoff "Cognitive Models and Prototype Theory"; Women, Fire and Dangerous Things) and Ronald Langacker (Concept, Image, and Symbol; Foundations of Cognitive Grammar), which have been acclaimed as making bridges and interfaces with multifarious disciplines, such as philosophy, anthropology, sociology and education sciences, neurology and artificial intelligence, collectively termed as cognitive sciences. Their discoveries, conclusions and presumptions can be useful to ponder upon, inter alia, how the individuals as members of societies subjectively perceive and intersubjectivity create the social world and thereby their individual identities.

For the study of self-related concepts, the awareness is indispensable, in accordance with Neisser's ("Concepts and Self-Concepts" 11) belief, that (1) the experience of the self is inseparably intertwined into the structure of language and contained in the self-description, (2) the self is conceptualized in different ways depending on culture, and that (3) there is a phenomenological variability in the ways how the self is experienced by particular individuals. The fact that the self is always defined by its history and culture is also stressed by Lakoff ("The Internal Structure of the Self" 92-93). According to him, cognitive linguistics cannot explain 
who particular human individuals are; it can, however, demonstrate how the internal structure of the self is conceptualized. Lakoff notices that, thanks to the Western philosophical tradition, there is a conventional system of conceptual metaphors that characterizes how the self is conceptualized in European languages. In conformity with the distinction between the self as subject and object, the essence of who the human individual is, as Lakoff ("The Internal Structure of the Self" 92) emphasizes, constitutes a "locus of consciousness and rationality", or "a radically free transcendental ego that is separate from and 'transcends' the physical body with its desires, passions, and needs". It is thus "the locus" of the subjectivity of the individual, referred to as "the subject", who does not have any physical substance, is free to reason, especially as the reason is universal and transcendent, not bound to bodies, and/or cultures. The body is in view of that an object that functions in conformity with the laws of nature.

Lakoff ("The Internal Structure of the Self" 92-110) analyses selected everyday expressions in which conceptual metaphors describe different states or properties of the self as subject and object. As he argues, a person can be divided, while the subject can be objective, what the following sentences exemplify: step outside yourself, take a good look at yourself, you should see yourself as others see you, etc. Analogously, the self can lose itself in some activity, or cease to be in control of doing something, what follows from the sentences: I lost myself in dancing, or I don't know what possessed me to do that, and also he was possessed by the devil or he's in the grip of his past. People, as the split selves, sometimes experience two or more inconsistent sets of values, that cannot be satisfied simultaneously and/or immediately, hence they produce such constatations as: I keep going back and forth between my scientific self and my religious self, or he's at war with himself over whom to marry, etc. People sometimes experience the lack of satisfaction with the kind of life they are leading, or try to realize some of their aspects, as it may be concluded on the basis of the statements: he found himself in writing, or I'm trying to get in touch with myself, etc. Similarly, people sometimes apologize for acting inconsistently with their real selves, for example, I wasn't myself yesterday. Experiencing the two inner selves means to refrain from expressing one's own true feelings for fear that they hurt or offend another person, what is communicated in the sentences: You've never seen what he's really like on the inside and She's sweet on the outside and mean on the inside. People are sometimes faced with a dilemma to betray themselves or to be true to themselves, when they say: I let myself down, I disappointed myself, or instruct somebody: be true to yourself, etc. There are also expressions that point out a lack of normal conscious self-control of the self (the absent self), for example, he's spaced out, I kept floating off in lecture, I'm on cloud nine, I'm high as a kite, etc., or to different aspects of the self, attending to different concerns (the scattered self), for example, he's all over the place, he's not focused, etc. Admittedly, there are also conceptualizations of the imposition of the own judgments and 
values on other persons (If I were you, I'd hate me/myself), metaphors for comprehending and expressing empathy (If I were you, I'd be depressed too, I know just how you feel), conceptualizations of subject and person as two people in the same body (I talk things over with myself before I do anything important), etc. As Lakoff suggests, a huge number of conceptual metaphors of two kinds - the divided person metaphors and metaphors that conceptualize the lack of a single unified self-concept - are used in everyday communication. What has to be stressed, even conceptions of the self, which are disseminated only in the Western culture, appear to be partially inconsistent and contradictory in terms of relation between subject and object. Therefore, on the basis cognitive linguistics investigations, "one single monolithic, self-consistent, correct cultural narrative" of what a person is cannot be devised.

\section{On selected philosophical approaches to self-consciousness and identity}

Anyhow, the abilities of conceptual thinking and categorization typical of humans, allowing them (self-)identification, result from the nature of the human self. The notional scope of the term self is specified in conformity with the assumption that each human being is a source and, at the same time, an object of his or her own consciousness. In philosophy and psychology, this term refers also to dispositional properties of a self-conscious subject who emotionally and intellectually experiences his or her outside world.

The notions of human personal identity and human self have been addressed by philosophers in terms of internal causality, the first person experience, biological conditionings and embodied existence, bodily continuity and psychological continuity, reflection, introspection, (self-)perception, (self-)interpretation in narratives, etc. Philosophical debates on personal identity go back to the attempts to fathom the nature of the human person made by the European thinkers from the early Middle Ages, through the periods of Reformation and Enlightenment to the twentieth century, discussed, for example, by Charles Taylor (Sources of the Self), Shaun Gallagher ("Introduction: A Diversity of Selves" 1-29, especially 12-16), John Barresi and Raymond Martin ("History as Prologue: Western Theories of the Self" 33-56). In their meditations on the relationships between self and identity, they have mostly paid attention to the unity of the self and its temporal extension, or duration in time. Thus, being influenced mainly by the beliefs of Plato (429-347 B.C.), for whom the self was the highest entity or immaterial substance able to survive bodily death, St. Augustine of Hippo (354-430) assumed the formation of the primordial identity of the soul out of its existence (cf. also Kehr "The Doctrine of The Self in St. Augustine and in Descartes"). Taking this particular viewpoint implies, according to Matthew Drever (Image, Identity, and the Forming of the Augustinian Soul, e.g., 24-25), 
that the identity is given to the immaterial, intelligible soul, inside of which it is shaped through an imaginary awareness of God's presence in the world. Hence, the identity of the soul is not equal to the identity of material things, based on likeness or similarity between them. In turn, the evaluation of daily life in relation to man as the center of universe in the Renaissance caused a change in the mentality of mankind and resulted in the awakening of the responsibility of individuals for their actions and, accordingly, the understanding of their identities (as discussed insightfully by Taylor (Sources of the Self 211-218). The Enlightenment conceptions of the human being and its place in the world were connected with the realization of the role of senses in providing data for perception, sensual impressions for the constitution of ideas, and reflection and reasoning for the understanding of the complexity of thought and for coming into being of the individual mind. Philosophers have developed the ideas of John Locke (1632-1704) for whom the so-called punctual self, endowed with radical reflexivity, is able, as described by Taylor (Sources of the Self 171-172), to objectively monitor and even manipulate its own conscious thoughts, longings and inclinations as if they were extrinsic to it. In Locke's view (cf. An Essay Concerning Human Understanding), the self, extended in time, is understood as a process of constantly changing psychic-emotional, rational and physical elements co-related to one another through the succession of developmental stages uniting the past to the present and future. This view implies that reasoning as a mental process or procedure, involving consciousness and memory, allows the human individual to make sense not only of the external world, but also even of his or her own mind.

One owes to the Western philosophical tradition approaches to and views of personhood, the self and identity, which may be shortly summarized as follows. The identity of a person in time, at different stages of his or her life, is determined rather by his or her relatedness to other persons and/or things than the physical or psychological relatedness of stages or states in his or her development to one another. Taking into account Derek Parfit's argumentation, namely that there are no appropriate criteria for self-identification (cf. Reasons and Persons, On What Matters; "The Unimportance of Identity" 419-441), it is right to point out that the personal identity is explainable in terms of what primarily matters in survival of human individuals when they face the menace of ceasing to exist. The question arises then whether they would be willing to count on finding extensions of themselves in other persons while appreciating the continuation of their original personality as much as they value their own existence (cf. especially Barresi and Martin "History as Prologue: Western Theories of the Self" 41-42). In conformity with Parfit's reasoning -that he conducted to some extent on the basis of thought experiments - the upholding or sustaining their personal identity, not reducible to brain and body, would mean for most people their wish to preserve themselves through the future existence of another person rather than to survive without psychological continuity and connectedness with immediate family, closest friends, objects of immediate surroundings, etc. 
The topic of environmental immersions of the corporeal self is still taken up by philosophers in sometimes intriguing manners, maybe because of its significance for someone's sense of personal identity. The issue of the bodily self immersed in the physical environment has been raised by Bas C. van Fraassen ("Transcendence of the Ego ..."), who supports his argumentation through fictitious, paradoxical illustrations. Depicting, for example, an imaginary knight who has no body, but a horse and an armor, and his squire who, being unable to distinguish himself from his material surroundings, feels like a prisoner of the physical world, van Fraassen ("Transcendence of the Ego ..." 458-459) claims that, firstly, someone who has no body does not exist and, secondly, the human individual who exists is, as a rule, faced with the necessity to realize his or her existence. The awareness of one's own body must be thus considered equal to the awareness of one's own existence, especially as it leads to self-preservative reactions or behavior. Similarly, the sense of selfpreservation of the individual can be concluded on the basis of his or her behavior.

Accordingly, as van Fraassen ("Transcendence of the Ego ..." 458) argues, the body is the most obvious thing seen by people who look at it, and, at the same time, human existence is embodied, simply because the human person has a material body that seems in some way indistinguishable from the material surrounding. Since the human person lives in the material world, the problem of the demarcation between his or her body and the rest of nature arises. It amounts to the question of what in the world is my body?, usually discussed with regard to physical, phenomenological, psychological criteria as well as criteria of social construction.

Having distinguished between manifestation and identity, van Fraassen ("Transcendence of the Ego ..." 464-465) explains that there is in fact only a graduated and nuanced relation between human individuals and the things, whether physical, psychological, or social, they call theirs. He himself appreciates the importance of the body for answering the question of - literally - what I am? As a matter of fact, as one expresses him- or herself bodily through posture, motion, speech, writing, and other work and art, as well as through parts of body in the extended sense, that is, clothes, employed artifacts, utensils and vehicles, places of residence and living space, properties and possessions, an unambiguous definition of what the self is seems to be difficult. Quite another question - formulated as how do I relate to my body? - concerns incarnate forms of expression and revelation of the self. Ultimately, one has thus to realize the importance of bodily features and movements, bearing in mind above all that the interaction between natural and social environments, as well as mutual interactions between particular selves, take place through their physical comportment. Self-expression takes place in language in a very broad sense, including body language and at the same time, cultural manifestations of individual communication forms and styles that are possible only in a community being cemented as such by the interpersonal function of language. Hence, one can rightly say that self-expression has always social aspects. 
In consequence, the fact that there is a continual relationship between the empirical self and its environment does not mean that the rational self is not able to transcend the reality which is given to it in a direct experience. Indeed, the self as a whole always manifests in nature, not only through its body but also its movements, words, decorating and clothing activities, artistic endeavors and literary output, passions, tantrums, etc.

\section{Personal vs. social identity of human selves}

The importance of someone's individual history, memories and also unconscious states for the sense of its individual identity was particularly accentuated by psychologists, who conducted analyses of the human psyche. From among them, Sigmund Freud (1856-1939) and Erik H. Erikson (1902-1994) have to be exposed here as pioneers of psychoanalysis and personality theories. Freud's observations of his patients have contributed to the strengthening of the view that the self-identity of an individual grows up from biological forces as it is indispensable for the motor coordination and self-preservation as a living organism. Its emergence in early childhood is, however, according to Freud (The Ego and the Id), grounded in conscious and unconscious states of individual mind and its sense is subordinate to the conscience of the particular human being. In Erikson's (cf. Identity and the Life Cycle; Identity, Youth, and Crisis) view, identity formation, even though most significantly stimulated by personal experiences lived in adolescence, takes place, from infancy to late adulthood. It is thus a lifelong process that influences the personality of the individual.

Psychologists take for granted that cognitive and behavioral processes of humans, including attention and memory, are substantially dependent on their affects and emotions, attitudes, needs, purposes and desires, expectations and ambitions, values, etc. The multiple states of the self are, in accordance with Abraham $\mathrm{H}$. Maslow's ("A Theory of Human Motivation" 370-371; cf. also Motivation and Personality) depiction, linked to its goals which can be either unconscious, as basic goals, or conscious as well as to secondary motivations, learned as resultant from its own life's experiences. For Maslow, internal states of self-awareness and behavior of human selves, dependent on their particular needs and goals, are decisive for their sense of identity. Moreover, one of the basic needs human individuals have is the need for a sense of identity. In his theory of human motivation, the individual as a biological organism, psychic being and an integrated whole is treated as determined by biological, cultural and situational factors. Maslow's approach to human nature implies that organismic states of humans, either motivated or motivating, are decisive for the states of their conscious appreciation. Since each behavior leads to a simultaneous expression and/or satisfaction of several fundamental and also higher 
needs, it is usually guided by more than one reason or purpose. In conformity with a humanistic psychology that exposes personal inclinations for self-discovery and self-actualization, the individual self searches for his or her identity in contacts with other people. As social beings, humans define themselves in terms of how others view them.

In the phenomenological approach of Carl Rogers (cf., inter alia, ClientCentered Therapy, On Becoming a Person), who was particularly interested in how humans realize their potential, the individual is to be considered as an experiencing person who always strives to maintain and enhance his or her organism. Being able to exert an internal control over his or her feelings and behavior, the individual grows and matures in a supportive environment. Focusing on the notion of self-actualization, Rogers (cf., e.g., On Becoming a Person 232-240) pays attention to the changing self-perception of the individual who, over time, becomes oneself in the ever-changing environment. A necessary condition for the personal development is, for Rogers, the possession of the ideal self that serves the individual as a reference point in making choices pertaining to him- or herself and his or her life. Human individuals act thus under the guidance of their idealized self-images, that is, perfect selves they aspire to be, and/or believe they are expected to become.

As far as, from a phenomenological point of view, individual identity finds support and expression in bodily activities of the self, for sociologists, it is principally a result of the life of an individual in society, the impacts of social environment, or forces, and his or her activities as members of social groups. It is thus considered in terms of group membership, social positions which individuals possess in society and culture, interpersonal relations as well as roles they play in societies, regarded as pivotal for their identification with social, cultural, ethnic, religious groups. The belief that the meaning of identity is negotiated implies that it arises as social roles are adopted, or learned by individuals who adjust to social situations. Correspondingly, the social identity is understood as such a collection of group membership that defines its individuals in particular.

In the argumentation of Douglas T. Kenrick, Steven L. Neuberg and Robert B. Cialdini Social Psychology 394-396), the self-image of an individual depends not only on his or her personal identity but also on social identity resulting mainly from their beliefs about and attitudes towards communities with which they identify. As the psychologists maintain, it is important to be aware that belonging to a given group significantly influences the attitudes towards oneself as an insider as well as towards the members of one's own group and other groups as outsiders. In social identity theories, following the studies conducted by Henri Tajfel and John C. Turner ("The Social Identity Theory of Inter-Group Behavior"), the matters of showing preference toward one's own group and prejudice against alien groups are submitted for consideration. 
Since the issues of intrinsic motivation have riveted attention of psychologists from Maslow's times on, one has to separately comment on the results of contemporary research into economic decision making, conducted, for example, by Vladas Griskevicius and Douglas T. Kenrick ("Fundamental Motives: How Evolutionary Needs Influence Consumer Behavior" 372-373). As social psychologists, they are almost certainly right while concluding, on the basis of consumers' behavior, that humans, regardless of time and place, have inherited psychological adaptations for solving some ancestral challenges, such as evading physical harm, avoiding disease, making friends, attaining status, acquiring and keeping a mate, and caring for the family. This implies that deep-seated evolutionary motives influence the behavior of modern man as well, sometimes in an unconscious way. The investigative framework proposed by Griskevicius and Kenrick seems, in their opinion, empirically very fruitful, especially as the analysis of preferences, behaviors, and decision processes of the individual, inferred from his or her behavior and decisive for their sense of individual identity, change in predictable ways depending on which of the fundamental motives are active at a particular moment.

\section{Identity as the result of time-binding activities of the human self}

Describing the human organism, being engaged in thinking, feeling, selfmoving, and electrochemical activities as continuous transactions with its space-time environment, it seems crucial - in the context of deliberations on how to form and express its identity - to go back to the definition of man as a "time-binding class of life". Being devised by Korzybski in his book Manhood of Humanity (60, 66-92), this definition is an original contribution to the understanding of individual and social identities as products of culture expressed through language and other social codes. In order to figure out what Korzybski meant by his depiction of man, one has to rethink his divagations pertaining to the meaning of the word to bind that refers to a process or operation, not equal to a mere addition of some elements, in effect of which a completely new quality or structure comes into being. Korzybski believed, as indicated by Bois (The Art of Awareness 180-188), that the capacity to bind together elements of a very different nature is characteristic of all forms of life. Thus, plants, the lowest form of life, are binders of chemicals. Animals, the next higher form of life, are binders of elements scattered in space, in brief, space-binders, because they are capable of moving to find food or water and gathering materials from its surroundings to build a nest or storehouse. But exclusively man as a time-binder, in addition to two abilities of lower-order forms of life, to bind chemicals and to bind space, knows how to select and put together elements that belong to different periods of time into new products or creations. Man combines elements available to him, transforms them, making out of them what did not exist before, and conse- 
quently, lives in the world created through his activities. The following quotation excerpted from the book The Art of Awareness by Bois deserves here special attention, as it depicts man as a member of a culture or society, and an ensemble of idiosyncratic traits:

"I am all of this at the same time, as if I were made of many concentric shells that have grown within an outer shell, until the center of my personal ego takes shape within the inherited environment - physiological, mental, affective, spiritual - that is an integral part of my total self. I can see myself as a cumulative cluster of experiences, structured in a unique manner, that exists nowhere else in space-time, that never existed before, and that will never be duplicated exactly at any other time in the totality of the ongoing cosmos. In a sense, I can say that I constitute a miniature world of my own, a world that I could destroy if I wanted to, a world that I can possibly modify and transform by my own initiative and decision to the degree that is probably beyond what I have learned to believe." (cf. Bois The Art of Awareness 191)

As one may deduce from Korzybski's and Bois' reasoning, the human self is to be regarded as a unique integrative set of characteristics which develops in the course of its search for understanding, explaining or interpreting its existence modes as a whole organism. Similarly, its mental activities of perceiving, thinking, remembering, planning, evaluating, feeling, etc., which depend on organismic processes being responsible for both the accumulation of its experiences and the intergenerational transmission of knowledge, might be seen as prerequisites of its sense of individuality and identity.

\section{Continuity, integration, identification, and differentiation as dimensions of identity}

The question what it practically means for the individual to have identity, has led social psychologists to the interpretation of human behavior which takes place in communicative events determined by concrete social situations. In keeping with John P. Hewitt's (Dilemmas of the American Self 152) statement that the individualities of selves as persons are socially constructed, one can ponder human identity as resultant from at least three abilities: (1) to maintain a balance between similarity and difference in the face of the growth of the individual and ever-changing social circumstances, (2) to be an integrated person who does not split into roles, but remains true to oneself, and (3) to maintain continuity and integrity in spite of the participation in a versatile social life. Importantly, identity, either conscious or unconscious, is featured by such dimensions, as continuity, integration, identification, and differentiation resulting from the objectifications of self in relation to specific aspects of its existence. 
Among particular features of identity, continuity is the impression that what a person is doing, thinking or feeling is temporally related to his or her past and future experiences, and integration is the conviction that his or her activities, thoughts and feelings constitute a certain coherent whole. Furthermore, identification, in this particular context, is the perception of oneself as a member of a certain group of community, in which he/she occupies a certain place among others, with whom he/she shares his/her thoughts, feelings, and actions. Ultimately, differentiation is a sense of noticing boundaries between self and others and some independence from others, connected with the ability to perceive differences between self and others. To conclude, one can agree that individuals who have a strong identity, knowing principally who they are and what they have to do, act decisively without a high degree of self-consciousness, that is, without having consciously to formulate their sense of individuality or group membership.

Having viewed identity within the systems of meaning created by human individuals, Hewitt (Dilemmas of the American Self 153-154) subsequently considers it as an internally motivational force, a combination of impulsive responses of the individual to external objects and events, or an organization of his or her sensitivities to the outside world without which no activity could proceed. Human beings have, as Hewitt maintains, no direct consciousness of their identities because in fact they do not have direct consciousness of any other aspect of their mental organization. They become conscious of identity only then when they have the possibility to realize consequences of their behavior and/or attempt to direct it. Nevertheless, becoming conscious of themselves through acting within particular situations, human individuals have explicit feelings of wholeness, continuity, identification, and differentiation.

In this sense, identity is a product of self-consciousness that emerges as an internally realized feeling just then when the individual becomes aware of his or her lived experience of existential relationality. Following Hewitt's reasoning, identity can sometimes be problematic for all people, and particularly for those living in the modern world. There are, however, situations and acts which do not evoke special feelings of identity, allowing individuals to remain conscious of self within a takenfor-grated identity. Examining human individuals as social selves who act within single, collectively defined situations, such as a baseball game, a family dinner, etc., social psychologists eventually assume that identity is both a necessary condition for action and a product of the situation itself. In real-life situations, the self is experienced because it is more or less equivalent to the role it plays; it is given continuity because the single situation provides a context for the duration of interaction, and, this way, sustains an identity. Hence, the concept of role, defined according to the behavioral expectations attached to a social position (or status) of a particular participant of a specified communicative event, is the key to the so-called situational identity (cf. especially Hewitt Dilemmas of the American Self 151-164). 
Accordingly, human individuals as communicators can create, maintain and/or challenge their identities in the face of the following circumstances. Firstly, social interaction sometimes entails going beyond the own perspective in order to see the situation from the perspective of the other. Secondly, the individual engaged in a given activity within a given social situation is sometimes constituted by this kind of activity so that he or she is in consequence fully concentrated on being this particular person and not another. Hence, the social role is a perspective that makes the individual at least temporarily a whole, integrated person. Thirdly, events, in a defined situation, occur and make sense sequentially; as such, they confer upon the person their temporal logic. Fourthly, in social situations, human beings can face problems related to their identities, because of three main reasons, such as an inescapable evaluation of their conduct by self and by others, a constant exposition of their identity to challenge, and permanent tensions between identification and differentiation, occurring even in those situations where common goals are clear and all accept them. One has to be aware that human individuals who have the capacity for negation and/or refusing to adopt, sometimes conceive self-interests as opposed to the interest of the group. Moreover, their conduct mostly takes place in communicatively defined situations, none of which is fully unproblematic. In reality, some episodes may interrupt ongoing activities and in effect, rather improve the identities of individuals then reveal their character. Just all these circumstances accompany the transformation of the consciousness of self into the consciousness of identity, or of one of its dimensions. To be added is that, fifthly, situated identity is tied to the maintenance of a defined situation in its usual and routine course; when participants sustain the situation then, their identities are not in question, And, finally, when a situation becomes problematic, the identities it contains become problematic as well.

While summarizing the achievements of social psychologists to the understanding of individual identity, it is right to stress, after Hewitt (Dilemmas of the American Self 163), that social interaction generates consciousness of both self and identity. The conduct of communication participants is controlled through role-taking guarantees, if they are conscious of themselves in their roles. Through the imagination of their appearances and possible actions from the positions of others, they objectify themselves; the objects they become to themselves are principally shaped by their roles. And because individuals may fail in their role performances, because there is a tension between identification with and differentiation from others, and because the definition of the social situation can fail or be transformed, selfconsciousness is sometimes determined by personal integration, continuity, identification, and differentiation. In sum, the sense of individual identity is problematic not only because the social life involves many different situations and roles; also the transition from one situation to another may pose a challenge to the identity of the individual. 


\section{A hypostatic approach to multiple aspects of identity}

In order to enrich the discussion about the multiple-identity dimensions of the human self, one should additionally mention the conception of a hypostatic personality, offered by Codrin Ștefan Țapu, a Romanian psychologist, for therapeutic purposes. In view of the multiaspectual character of personality, Țapu proposes to treat the mental acts of human individuals as the processes of self-identification in which they construe themselves in terms of hypostases. By reference to the specialist term hypostasis, which means, in mathematical logic, an abstractive objectification or reification of relational properties of concrete objects which constitute their essence not existing in reality, Țapu aims at providing a potential explanation of how to approach the multi-attributive individuality and uniqueness of humans as persons (cf. Țapu Hypostatic Personality 13). Even though Țapu did not specify his predecessors or sources of inspiration, it was undoubtedly Charles Sanders Peirce (18391914), an American philosopher, logician and mathematician, the founder of pragmatism, who introduced the definition of the hypostatic abstraction as a concept of formal logic (cf. CP 4.235, „The Simplest Mathematics” of 1902, in Collected Papers, CP 4.227-323). According to Peirce, objects of thought are subjectively formed through logical operations, known as hypostasis, where the predication about a relational property is transformed into its substantivization; to be more exact, in linguistic terms, it is the process of grammatical converting of adjectives into substantives. Therefore, the personality of the individual, or his or her identity, is a hypostatic object of thought or talk. Worth adding is here the statement of Thomas $\mathrm{L}$. Short, a renowned expert of Peirce's semiotics (cf. Peirce's Theory of Signs), that it was just this American pragmatist in question who "held that we have no direct knowledge of ourselves (or, as he said, of 'the inner world') but know ourselves only by "hypothetical reasoning from our knowledge of external facts"' (cf. "Hypostatic Abstraction in Self-Consciousness" 289).

Even though Țapu has aimed at defining and systematizing the notions which pertain to relations between mind and behavior rather than proposing an academic approach to the subject, his work opens new insights into integrative, synthetic and holistic studies of individual personality factors within a person. In Țapu's opinion (Hypostatic Personality 16-23), personality is continuously formed under the pressure of environmental conditionings. Factors that influence the doings and ways of being made of the human individual, such as (1) language, (2) cognition, (3) action, and (4) motivation, are examined, as components of personality correlated to appropriate systems in the brain, in terms of patterns of traits. They are treated as probably highly independent of the cultural background.

In accordance with Țapu's reasoning, the complex and multidimensional personality of each individual arises in effect of combination or interaction of its four 
components, which result from corresponding behaviors, such as (1) the cognitive activity of the individual, managed by its language and cognition, (2) the practical activity of the individual, managed by his or her language and action, (3) the affective activity of the individual, managed by cognition and motivation, and/or (4) the expressive activity of the individual, i.e., from facial expressions, gestures, tone of voice and other signs of emotions. The multidimensional self, described in terms of personality, takes shape between the processes of regulation, as it is coordinated by language and motivation, and the processes of adaptation, as it is coordinated by cognition and action. In other words, it functions in-between psychic events taking place between regulation and adaptation processes of the individual.

From the viewpoint of Țapu's (Hypostatic Personality 13-21) psychological theory and practice, the individual is approached as an omni-hypostatic aggregate, or an entity embracing all possible hypostases of an ensemble. Hypostases are defined as ways in which persons relate to the world, or forms of concrete manifestations of their personalities in their various dimensions, or specific existential modes of humans. In order to know, or discern, who, or how he or she is, or can eventually become, one has to take into account ways in which the individual presents him- or herself in lots of aspects, depending on the internal and external realities to which he or she relates.

The hypostatic approach allows to realize the multiplicity and complexity of the self as a person whose behavior changes depend on its biological and psychic states and social factors, and who may be viewed by others in different ways depending on changing contexts. Many of his or her properties and aspects are only seemingly invariable and well-balanced, which means that people are not one-sided, but rather are a combination of conflicting features and may unexpectedly transform depending on situations and multifarious conditions. People are and present themselves differently at different moments being determined by their biological states and the situation or environment, that is, other people and things surrounding them. In this context, one speaks about the hypostatic relations of the human mind, or the hypostatic nature of consciousness, bearing in mind that the contents of consciousness are mental representations of different aspects of the identity of particular individuals, which however have a tendency to overlap or to compete with one another.

Bearing in mind the unity of experiences as a defining feature of selfhood and a prerequisite of identity, one should specify circumstances that make the human individual to understand who he or she is. These are: (1) as a social actor, the individual performs roles in the presence of others, displaying, at the same time, his or her curtains traits, (2) his or her behavior is motivated by his or her internal desires and personal goals, values, and attitudes, and as such, future-oriented, (3) taking the first-person perspective, the individual becomes the creator of the autobiographical story about his or her life, encompassing the past, present, and future. 


\section{Final remarks on identity within the framework of communication studies}

To summarize the whole discussion featuring the content of particular subparts of the paper, the identity of human selves as communicating individuals may be approached solely through an assumptive description of their subjective awareness, i.e., arriving at their introspective reflection in relation to their environments but in abstraction from the subjectivity of other individuals. In fact, identity results from the human ability to perceive one's own uniqueness with respect to one's own bodily conditions, experiences and habits, purposes and intentions, relations to the physical and cultural environments, place in time and space, etc. Having an identity means for the individual to possess a sense of unity of his or her own intellectual, emotional and volitional acts as reinforced through the continuity of his or her own recollections of the past with the consciousness of the present and the anticipated future. Deliberately or not, human individuals manifest their identities - which primarily find reflections in their thoughts - in speech, writing, gestures, etc., as observable aspects of complex semantic reactions of their organisms to all sorts of stimuli. At any rate, however, the sense of identity is for the individual selves a consequence of subjective meanings of their personal experiences, which constantly develop as objects of their thought and speech, finding their expression in mental and concreate acts of inner and outer communication.

While speaking about the forms of its expression through concrete behavior in communicative situations, the question arises how far the identity determines the patterns of interaction, and vice versa, how far the patterns of interaction may determine the identity of the individual. Bearing in mind the uniqueness and distinctiveness of human individuals as mental subjects and the multidimensionality of their personalities, one has to highlight the importance of intersubjective and interpersonal contacts, in which individuals learn how to view themselves, or how to form and change their identities in relation to others. One has to remember that they can reinforce or modify their identities at different levels of communication, especially as they choose to acquire and/or rethink certain contents, ignoring or overlooking a number of related facts and events. As communication involves impression management and self-presentation, individuals sometimes intentionally convey a reliable image of themselves to others. Since the sense of identity implies the unification or integration of human individuals in their existence, the distinctiveness and changeability of their personalities may become visible only in the course of their collective life when they create interpersonal and intersubjective relationships and form communities of different kind. Assuming that complex and multifaceted identities arise thanks to personal experiences gained through group membership and social practices, it is difficult to judge whether identity influences communication or whether it results from communication. Nevertheless, it is true that identities 
are negotiated, managed, or manipulated in specific social encounters and communicational settings. At any rate, identities are grounded on interpersonal and intersubjective relations. As such, they can be discovered and described in relational terms showing the mechanisms of social power in terms of interpersonal communicators perceptions.

\section{References}

Barker, L.L. 1978. Communication. Englewood Cliffs, NJ: Prentice-Hall.

Barresi, J. and M. Raymond. 2011. "History as prologue: Western theories of the self". In: Gallagher, Sh. (ed.). The Oxford handbook of the self. New York: Oxford University Press. 33-56.

Bois, J.S. 1966/1972. The art of awareness: a text on general semantics and epistemics. Second edition. Dubuque, IA: W.C. Brown.

Brentano, F. 1874. Psychologie vom empirischen Standpunkt. Leipzig: Duncker and Humblot.

Bühler, K. 1934/1990. Theory of language. The representational function of language. Trans. Donald Fraser Goodwin. Amsterdam, Philadelphia: John Benjamins (Foundations of Semiotics 25). [Sprachtheorie. Die Dastellungsfunktion der Sprache. Jena: Gustav Fischer.].

DeVito, J.A. 1976. The interpersonal communication book. New York, (etc.): Harper and Row.

Drever, M. 2013. Image, identity, and the forming of the Augustinian Soul. Oxford: Oxford University Press.

Erikson, E.H. 1959. Identity and the life cycle. Selected papers with a historical introduction by David Rapaport. New York: International University Press.

Erikson, E.H. 1968. Identity, youth, and crisis. New York: Norton.

Fraassen, B.C. van. 2005. "Transcendence of the ego (The non-existent knight)". In: Strawson, G. (ed.). The Self? Malden, MA; Oxford, UK; Carlton, VIC: Blackwell Publishing. 87-110.

Freud, S. 1923/1960. The ego and the id. Trans. Joan Riviere. New York: W. W. Norton and Company, [Das Ich und das Es. Leipzig. Wien, Zürich: Internationaler Psychoanalytischer Verlag].

Gallagher, Sh. 2011. "Introduction: a diversity of selves". In: Gallagher, Sh. (ed.). The Oxford Handbook of the Self. Oxford: Oxford University Press. 1-29.

Griskevicius, V. and D.T. Kenrick. 2013. "Fundamental motives: how evolutionary needs influence consumer behavior." Journal of Consumer Psychology 23.3. 372-386.

Hewitt, J.P. 1989. Dilemmas of the American self. Philadelphia: Temple University Press.

Kehr, M.W. 1916. "The doctrine of the self in St. Augustine and in Descartes." The Philosophical Review XXV.4. 587-615.

Kenrick, D.T., Neuberg, S.L. and R.B. Cialdini. 1999/2002. Social psychology. unraveling the mystery. Boston: Allyn and Bacon.

Korzybski, A. 1923/1995. Manhood of humanity. Lakeville, Conn. International Non-Aristotelian Library.

Korzybski, A. 1933/1994. Science and sanity. an introduction to non-Aristotelian systems and general semantics. New York: International Non-Aristotelian Library.

Lakoff, G. and M. Johnson. 1980. Metaphors we live by. Chicago, London: Chicago University Press.

Lakoff, G. 1984/1987. "Cognitive models and prototype theory". In: Neisser, U. (ed.). Concepts and conceptual development. Ecological and intellectual factors in categorization. New York, Cambridge: Cambridge University Press. 63-100.

Lakoff, G. 1997. "The internal structure of the self". In: Neisser, U. and D.A. Jopling (eds.). The conceptual self in context. Culture, experience, self-understanding. Cambridge: Cambridge University Press. 92-113. 
Lakoff, G. 1987. Women, fire and dangerous things. What categories reveal about the mind. Chicago, London: Chicago University Press.

Langacker, R. 1990. Concept, image, and symbol: the cognitive basis of grammar. Berlin, New York, NY: Mouton de Gruyter.

Langacker, R. 1987/1999. Foundations of cognitive grammar. Vol. I. Theoretical prerequisites. Stanford, CA: Stanford University Press.

Lock, A. and K. Symes. 1996/1999. "Social relations, communication, and cognition”. In: Lock, A. and Ch.R. Peters (eds.). Handbook of human symbolic evolution. Oxford, UK: Clarendon Press / New York, NY: Oxford University Press / Oxford, UK, and Malden, MA: Blackwell Publishers. 204-235.

Locke, J. 1960/1975. An essay concerning human understanding. Oxford, UK: Oxford University Press. Maslow, A.H. 1943. "A theory of human motivation". Psychological Review 50. 370-396.

Maslow, A.H. 1954/1970. Motivation and personality. New York: Harper and Row.

Neisser, U. 1997. "Concepts and self-concepts". In: Neisser, U. and D.A. Jopling (eds.). The conceptual self in context. Culture, experience, self-understanding. Cambridge: Cambridge University Press. $3-12$.

Neisser, U. 1988. "Five kinds of self-knowledge." Philosophical Psychology 1. 35-59.

Neisser, U. 1967. Cognitive psychology. New York: Appleton-Century-Crofts.

Parfit, D. 2011. "The unimportance of identity". In: Gallagher, Sh. (ed.). The Oxford Handbook of the Self. Oxford: Oxford University Press. 419-442.

Parfit, D. 2011. On what matters. Vol. I and II. Oxford: Oxford University Press.

Parfit, D. 1984. Reasons and persons. Oxford: Oxford University Press.

Peirce, Ch.S. 1902. "The simplest mathematics". In: Hartshorne, Ch. and P. Weiss (eds.). Collected papers of Charles Sanders Peirce, vols. 1-6, 1931-1935; and In: Burks, A.W. (ed.). vols. 7-8, 1958. Cambridge, MA: Harvard University Press. 227-323 (abbreviated as CP 4.227-323).

Rogers, C.R. 1951. Client-centered therapy. Its current practice, implications and theory. Boston: Houghton Mifflin.

Rogers, C.R. 1961. On becoming a person. A therapist's view of psychotherapy. Boston: Houghton Mifflin.

Rolfe, L. 1996/1999. "Theoretical stages in the prehistory of grammar". In: Lock, A. and Ch.R. Peters (eds.). Handbook of human symbolic evolution. Oxford, UK: Clarendon Press / New York, NY: Oxford University Press / Oxford, UK, and Malden, MA: Blackwell Publishers. 776-792.

Short, T.L. 1997. "Hypostatic abstraction in self-consciousness". In: Brunning, J. and P. Foster (eds.). The rule of reason: the philosophy of Charles Sanders Peirce. Toronto, Buffalo, London: University of Toronto Press.

Short, T.L. 2007. Peirce's theory of signs. New York, Cambridge: Cambridge University Press.

Tajfel, H. and J.C. Turner. 1979/1986. "The social identity theory of inter-group behavior". In: Worchel, S. and W.G. Austin (eds.). Psychology of intergroup relations. Chicago: Nelson-Hall. 7-24.

Țapu, C.Ș. 2001. Hypostatic personality: psychopathology of doing and being made. Ploiești: Editura Premier.

Taylor, Ch. 1999. Sources of the self: the making of the modern identity. Cambridge: Cambridge University Press. 